Check for updates

Cite this: RSC Adv., 2019, 9, 9253

Received 14th September 2018

Accepted 13th March 2019

DOI: $10.1039 / \mathrm{c} 8 \mathrm{ra0} 07661 \mathrm{~h}$

rsc.li/rsc-advances

\section{Poly(arylene ether)s with aromatic azo-coupled cobalt phthalocyanines in the side chain: synthesis, characterization and nonlinear optical and optical limiting properties}

\author{
Yuxuan Zhang, Saisai Gai, Zhonghui Wang, Shuang Wang, An Sui \\ and Xi-Ming Song (D) *
}

\begin{abstract}
A novel poly(arylene ether) with azo-coupled cobalt phthalocyanine in the side chain (PAE-azo-CoPc) was prepared by 1,2-benzodinitrile, anhydrous cobaltous chloride and a novel azobenzene-containing poly(aryl ether) (PAE-azo-DCN) via a nucleophilic substitution polycondensation based on a novel bisfluoro monomer, 4-[(3,4-cyanophenyl)diazenyl]phenyl-2,6-difluorobenzoate. The obtained polymers were characterized and evaluated by FT-IR, ${ }^{1} \mathrm{H}$ NMR, DSC and TGA. PAE-azo-CoPc exhibited higher glass transition temperature and better thermal stability than PAE-azo-DCN because of the introduction of cobalt phthalocyanine groups. The results of Z-scan measurements demonstrated that PAE-azo-CoPc showed reversible saturable absorption and positive refraction, and PAE-azo-DCN showed saturable absorption and negative refraction. By calculation, PAE-azo-CoPc exhibited larger third-order nonlinear optical susceptibilities than that of PAE-azo-DCN. The results of optical limiting measurements demonstrated that the PAE-azo-CoPc exhibited an excellent optical limiting response.
\end{abstract}

\section{Introduction}

With the fast development of laser technology, optical limiting materials, which could protect optical sensors and human eyes from harmful laser pulses, have received considerable attention..$^{1-4}$ Many kinds of optical limiting materials such as carbon nanotubes, graphene, azo-polymer, porphyrins, phthalocyanines and metal nanoparticles have been studied. ${ }^{5-12} \mathrm{~A}$ perfect optical limiting material requires fast response time, low limiting threshold, large nonlinear optical susceptibilities and high transmittance for low intensity ambient light. ${ }^{13,14}$ In addition, excellent mechanical properties and thermal stabilities are also necessary. Up to now, developing ideal optical limiting materials is still a challenge.

Polymers containing push-pull type azobenzene chromophores have received considerable attention due to their large third-order nonlinear susceptibility of the push-pull type azobenzene chromophores. ${ }^{15,16}$ The push-pull type azobenzene chromophores exhibit excellent third-order nonlinear optical properties because of their conjugate $\pi$-electron systems and good fluidity of $\pi$ electrons. Unless these, the easy processing and good mechanical properties of azo-polymers are also the reason why they have been considered as promising third-order nonlinear optical materials.

Liaoning Key Laboratory for Green Synthesis and Preparative Chemistry of Advanced Materials, College of Chemistry, Liaoning University, Shenyang, 110036, China. E-mail: songlab@lnu.edu.cn
Phthalocyanines (Pcs) was one of the most promising optical limiting materials because of their large nonlinear susceptibility. ${ }^{17-19}$ It is reported that the combination of azobenzene and phthalocyanines possessed the advantages of the two constituents and showed larger nonlinear optical properties than that of phthalocyanines in small molecules. ${ }^{20}$ However, it is difficult to fabricate optical devices with single phthalocyanines molecule, so many kinds of polymers have been selected as solid state matrices for phthalocyanines. ${ }^{21-23}$ However, the direct doping of phthalocyanines and polymers usually brings about poor dispersion and aggregation, which could lead to undesirable performance. In addition, most of the polymer matrices are vulnerable to high energy density laser due to their inferior thermal stabilities. Introducing the phthalocyanines into polymers with good thermal stability by covalent bond may be a helpful strategy to solve these problem..$^{24,25}$

Poly(aryl ether)s (PAEs) are a family of high-performance polymers with excellent thermal and mechanical properties. Functionalized PAEs have received considerable attention due to their potential applications in optical storage materials, fluorescent materials and proton-exchange membrane. ${ }^{26-29}$ However, only a little nonlinear optical materials and optical limiting materials based on PAEs have been reported, ${ }^{30-32}$ which need more development and research. In this paper, a novel optical limiting material with good thermal stability was designed and synthesized by introducing azobenzene chromophores and cobalt phthalocyanines into PAEs system. Firstly, 
azobenzene-containing poly(aryl ether) (PAE-azo-DCN) was prepared via a nucleophilic aromatic substitution polycondensation based on a novel bisfluoro monomer, 4-[(3,4cyanophenyl)diazenyl]phenyl-2,6-difluorobenzoate. Then, pol$\mathrm{y}$ (arylene ether)s with aromatic azo-coupled cobalt phthalocyanines in the side chain (PAE-azo-CoPc) was prepared by PAEazo-DCN, 1,2-benzodinitrile and cobaltous chloride anhydrous. The obtained polymers were characterized and evaluated by UV-vis, ${ }^{1} \mathrm{H}$ NMR, DSC and TGA. The third-order optical properties of PAE-azo-DCN and PAE-azo-CoPc were evaluated by Z-scan. And the optical limiting property of PAE-azo-CoPc was also investigated.

\section{Materials}

\subsection{Materials}

4-Aminophthalonitrile was purchased from Meryer (Shanghai) Chemical Technology Co., Ltd. 2,6-Difluorobenzoyl chloride was purchased from Ruiding Chemicals Co., Ltd. 4,4'-(Hexafluoroisopropylidene)diphenol (bisphenol AF) was purchased from Tianjin Heowns Biochemical Technology Co., Ltd. Cobalt phthalocyanine, cobalt(II) chloride, triethylamine and 1,2dicyanobenzene were purchased from Aladdin Chemistry Co. Ltd. All the solvents were purchased from commercial sources.

\subsection{Measurements}

${ }^{1} \mathrm{H}$ NMR spectra were recorded on a Mercury-Vx300-NMR instrument using DMSO- $\mathrm{d}_{6}$ as solvent, and the chemical shifts $(\delta)$ were given in ppm using TMS as internal reference. FI-IR spectra (KBr pellet) were recorded on a Perkin Elmer Spectre one FT-IR spectrophotometer. UV-visible absorption spectra were recorded on a Shimadzu UV-2501 UV-vis spectrophotometer. Glass transition temperatures $\left(T_{\mathrm{g}} \mathrm{S}\right)$ were determined by a Model Mettler DSC instrument under nitrogen atmosphere at a heating rate of $20{ }^{\circ} \mathrm{C}$ min. Thermo-gravimetric analysis was performed on a Perkin Elmer Pyris 1 TGA analyzer with a heating rate of $10{ }^{\circ} \mathrm{C}$ min and under nitrogen atmosphere.

The nonlinear optical property of the sample was evaluated by a Z-scan technique performed using a Q-switched ns Nd:YAG laser system continuum with pulse width of 5 ns at $10 \mathrm{~Hz}$ repetition rate and $532 \mathrm{~nm}$ wavelength. The solution of the sample was contained in a $2 \mathrm{~mm}$ quartz cell and moved along the axis of the incident beam ( $z$ direction). The incident and transmitted energies were detected simultaneously by an energy meter (Laser Probe, Rj-7620 ENERGY RATIOMETER, RjP-735). The optical limiting property was performed with the same Zscan technique system as in the nonlinear absorption experiments, where the intensity of the incident energy is varied continuously and the output energy is captured by a large aperture photodetector. The input energy was $16.5 \mu \mathrm{J}$.

\subsection{Synthesis}

2.3.1. Synthesis of 4-((3,4-dicyanophenyl)diazenyl)phenol (monomer 1) (monomer 1, Scheme 1). Monomer 1 was synthesized as follow. Hydrochloric acid $(0.4 \mathrm{~mol}, 33.6 \mathrm{~mL})$ was added into the mixture of 4-aminophthalonitrile (14.315 g, 0.1 mol) and $300 \mathrm{~mL}$ water. Then an aqueous solution of $\mathrm{NaNO}_{2}$ $(6.9 \mathrm{~g}, 0.1 \mathrm{~mol})$ was added at $0-5{ }^{\circ} \mathrm{C}$. The obtained solution was filtered and added into a mixture of $\mathrm{NaOH}(8.0 \mathrm{~g}, 0.2 \mathrm{~mol})$, phenol (9.4 g, $0.1 \mathrm{~mol})$, and $\mathrm{NaHCO}_{3}(25.2 \mathrm{~g}, 0.3 \mathrm{~mol})$ in $200 \mathrm{~mL}$ water. After the obtained mixture was stirred at $0-5{ }^{\circ} \mathrm{C}$ for $1 \mathrm{~h}$, hydrochloric acid $(0.4 \mathrm{~mol}, 33.6 \mathrm{~mL})$ was added into the final mixture. The resulting precipitate was collected and dried. The crude product was recrystallized from ethanol (yield: $58 \%$ ). IR $\left(\mathrm{KBr}, \mathrm{cm}^{-1}\right): 2239(-\mathrm{CN}), 3327(-\mathrm{OH}) ;{ }^{1} \mathrm{H}$ NMR $\left(\mathrm{DMSO}_{6}, \delta\right.$, ppm): 10.75 (s, 1H), 8.44 (d, 1H), 8.30 (d, 1H), 8.21 (d, 1H), 7.89 $(\mathrm{d}, 2 \mathrm{H}), 6.99(\mathrm{~d}, 2 \mathrm{H})$.

2.3.2. 4-((3,4-Dicyanophenyl)diazenyl)phenyl-2,6-

difluorobenzoate (monomer 2, Scheme 1). Under $\mathrm{N}_{2}$ atmosphere, a solution of 2,6-difluorobenzoyl chloride (8.8275 g, 0.05 $\mathrm{mol}$ ) in $30 \mathrm{~mL} \mathrm{CH} \mathrm{Cl}_{2}$ was added dropwise into a mixture of monomer 1 (12.4125 g, $0.05 \mathrm{~mol})$ and triethylamine $(5 \mathrm{~mL})$ in $80 \mathrm{~mL} \mathrm{CH} \mathrm{Cl}_{2}$. Then the mixture was refluxed for $20 \mathrm{~h}$. The resulting insoluble inorganic salt was removed by filtering. After evaporating the filtrate, the crude product was recrystallized from toluene, and the monomer 2 was obtained as red crystal (yield: 67\%). IR (KBr, cm ${ }^{-1}$ ): 2231 (-CN), 1749 (-CO-); ${ }^{1} \mathrm{H}$ NMR (DMSO-d ${ }_{6}, \delta$, ppm): $8.60(\mathrm{~s}, 1 \mathrm{H}), 8.39(\mathrm{~d}, 1 \mathrm{H}), 8.34(\mathrm{~d}, 1 \mathrm{H}), 8.12$ $(\mathrm{d}, 2 \mathrm{H}), 7.81-7.83(\mathrm{~m}, 1 \mathrm{H}), 7.62(\mathrm{~d}, 2 \mathrm{H}), 7.38(\mathrm{t}, 2 \mathrm{H})$.

2.3.3. Synthesis of azobenzene-containing poly(aryl ether) (PAE-azo-DCN, Scheme 2). Bisphenol AF (3.3623 g, $0.01 \mathrm{~mol}$ ), monomer 2 (3.8843 g, $0.01 \mathrm{~mol}), \mathrm{K}_{2} \mathrm{CO}_{3}(1.5201 \mathrm{~g}, 0.011 \mathrm{~mol})$, DMAc $(22 \mathrm{~mL})$ and toluene $(10 \mathrm{~mL})$ were put into a three-necked flask. The reaction mixture was refluxed at $130{ }^{\circ} \mathrm{C}$ for $3 \mathrm{~h}$ to ensure complete dehydration. After removal of toluene, the reaction mixture was heated at $150-160{ }^{\circ} \mathrm{C}$ for $8 \mathrm{~h}$. After being poured into the deionized water, the precipitate was collected and washed with hot water and ethanol several times. The resulting product was dried at $80{ }^{\circ} \mathrm{C}$ under vacuum for $24 \mathrm{~h}$ and PAE-azo-DCN was obtained as orange powder. The yield was $83 \%$.

2.3.4. Azobenzene-containing poly(arylene ether)s with phthalocyanine cobalt(II) in the side chain (PAE-azo-CoPc, Scheme 2). The synthetic procedure of PAE-azo-CoPc was shown as follows. For PAE-azo-DCN (0.5205 g, $0.002 \mathrm{~mol}), 1,2-$ dicyanobenzene $(0.436 \mathrm{~g}, 0.006 \mathrm{~mol}), \mathrm{CoCl}_{2}(0.1546 \mathrm{~g}, 0.002$ $\mathrm{mol})$ and quinoline $(20 \mathrm{~mL})$ were put into a three-necked flask. The mixture was heated at $210{ }^{\circ} \mathrm{C}$ for $8 \mathrm{~h}$ under nitrogen atmosphere. After being poured into methanol, the precipitate was collected by filtration. The crude product was washed with acetone, ethanol and deionized water. Then the crude product was collected by filtration and extracted by chloroform with a Soxhlet extractor. The chloroform solution was concentrated and precipitated in methanol. The resulting product was dried at $100{ }^{\circ} \mathrm{C}$ under vacuum for $24 \mathrm{~h}$ and PAE-azo-CoPc was obtained.

\section{Results and discussion}

\subsection{Synthesis and characterization}

We designed a new bisfluoro monomer (monomer 2) containing azobenzene group and the synthetic route of the monomer is illustrated in Scheme 1. The structure of monomer 2 was confirmed by IR and ${ }^{1} \mathrm{H}$ NMR, as shown in Fig. 1 and 2. The IR 


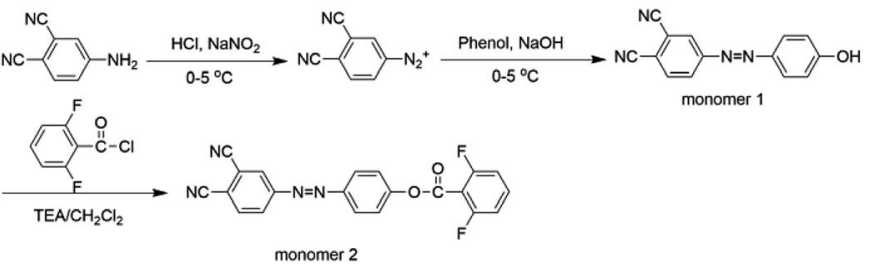

Scheme 1 Synthetic route of monomer 1 and monomer 2.

spectrum showed the characteristic bands of $-\mathrm{CN}, \mathrm{C}-\mathrm{F}$ and -CO- stretching vibrations at 2231, 1013 and $1748 \mathrm{~cm}^{-1}$, respectively. It also could be observed the characteristic bands of $-\mathrm{C}=\mathrm{C}$ - of benzene at $1624 \mathrm{~cm}^{-1}$ and $1588 \mathrm{~cm}^{-1}$. In the ${ }^{1} \mathrm{H}$ NMR spectrum of monomer 2, all of the signals are well agreement with the expected structure.

PAE-azo-DCN and PAE-azo-CoPc were synthesized as shown in Scheme 2. From Table 1, it could be seen that both PAE-azoDCN and PAE-azo-CoPc had number average molecular weights above $1 \times 10^{4} \mathrm{~g} \mathrm{~mol}^{-1}$. Both PAE-azo-DCN and PAE-azo-CoPc showed good solubility in common organic solvents such as tetrahydrofuran, cyclohexanone, dimethylacetamide, $\mathrm{N}, \mathrm{N}$ dimethylformamide and $N$-methyl-2-pyrrolidone.

The chemical structures of PAE-azo-DCN and PAE-azo-CoPc were confirmed by ${ }^{1} \mathrm{H}$ NMR and UV-vis spectra. Fig. 3 shows

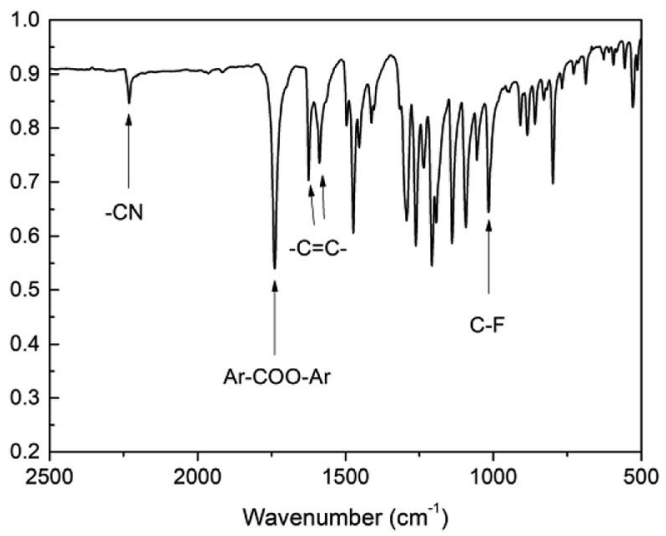

Fig. $1 \mathrm{IR}(\mathrm{KBr})$ spectrum of monomer 2 .

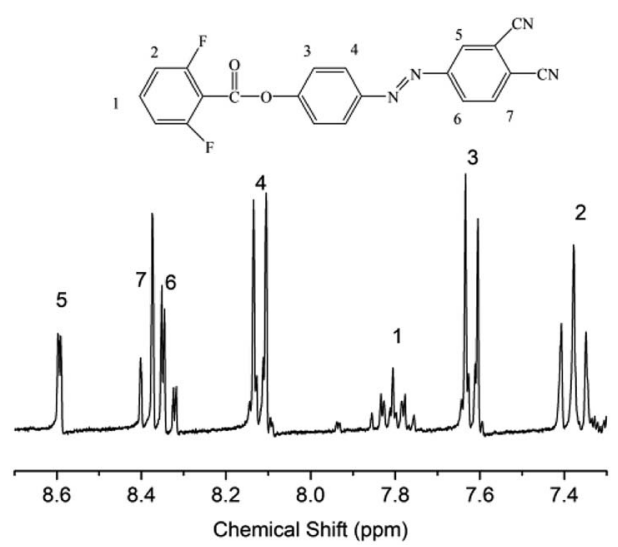

Fig. $2{ }^{1} \mathrm{H}$ NMR spectrum of monomer 2 in DMSO- $\mathrm{d}_{6}$.
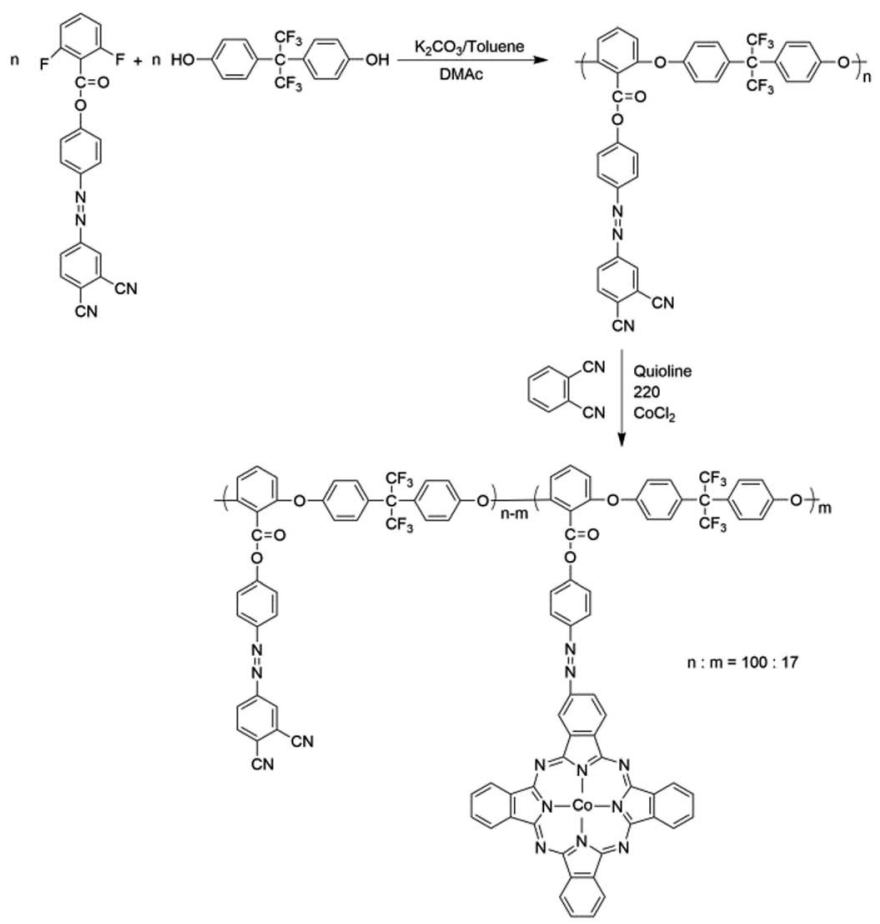

Scheme 2 Synthesis routes to PAE-azo-DCN and PAE-azo-CoPc.

Table 1 Properties of PAE-azo-DCN and PAE-azo-CoPc

\begin{tabular}{lllll}
\hline Polymer & $M_{\mathrm{n}}$ & $M_{\mathrm{w}} / M_{\mathrm{n}}$ & $T_{\mathrm{g}}{ }^{a}\left({ }^{\circ} \mathrm{C}\right)$ & $T_{\mathrm{d} 5}{ }^{b}\left({ }^{\circ} \mathrm{C}\right)$ \\
\hline PAE-azo-DCN & $1.01 \times 10^{4}$ & 1.5 & 158 & 381 \\
PAE-azo-CoPc & $1.05 \times 10^{4}$ & 2.1 & 164 & 387
\end{tabular}

${ }^{a}$ Glass transition temperature by DSC. ${ }^{b} 5 \%$ weight-loss temperatures were detected at a heating rate of $10{ }^{\circ} \mathrm{C} \mathrm{min}^{-1}$ in nitrogen.

typical ${ }^{1} \mathrm{H}$ NMR spectra of PAE-azo-DCN and PAE-azo-CoPc in DMSO- $\mathrm{d}_{6}$ with signal assignment. Compared to the ${ }^{1} \mathrm{H}$ NMR spectrum of PAE-azo-DCN, it was observed that the signals of protons a and b appear at $\delta 9.28$ and $8.87 \mathrm{ppm}$ in the spectrum of

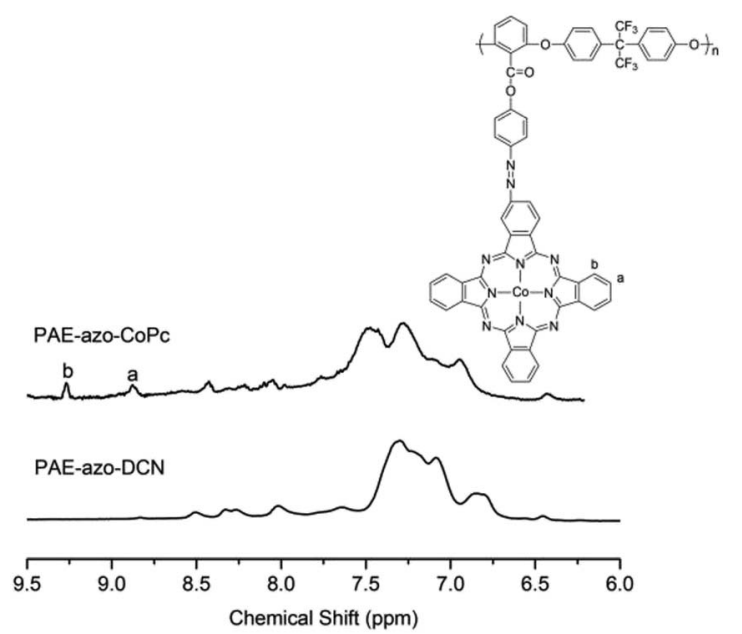

Fig. $3{ }^{1} \mathrm{H}$ NMR spectra of PAE-azo-DCN and PAE-azo-CoPc. 
PAE-azo-CoPc. The grafting ratio of the phthalocyaninecobalt unites is about $17 \%$ as estimated from the NMR characterization. The UV-vis spectra of PAE-azo-DCN and PAE-azo-CoPc in DMF solution are shown in Fig. 4. As shown in Fig. 4, the characteristic absorption bands at around $360 \mathrm{~nm}$ could be observed which corresponded to $\pi-\pi^{*}$ transitions resulted from the intramolecular charge transfer of the azobenzene groups. Compared to the UV-vis spectrum of PAE-azo-DCN, the UV-vis spectrum of PAE-azo-CoPc showed a new peak at around $664 \mathrm{~nm}$ corresponding to the characteristic absorption bands of phthalocyaninecobalt unites.

\subsection{Thermal properties of PAE-azo-DCN and PAE-azo-CoPc}

Fig. 5 shows the DSC curves of the polymers, and the corresponding experimental data are listed in Table 1 . Due to the aromatic structure, both PAE-azo-DCN and PAE-azo-CoPc showed high $T_{\mathrm{g}} \mathrm{s}$. Compared to the $T_{\mathrm{g}}$ of PAE-azo-DCN, $T_{\mathrm{g}}$ of PAE-azoCoPc increased from $158{ }^{\circ} \mathrm{C}$ to $163{ }^{\circ} \mathrm{C}$ after the introduction of phthalocyaninecobalt groups. Fig. 6 shows the TGA analysis curves of PAE-azo-DCN and PAE-azo-CoPc, and the detailed experimental data from the TGA analysis are also listed in Table 1. From Fig. 6 and Table 1, it could be observed that both of the $5 \%$ weight loss $\left(T_{\mathrm{d} 5}\right)$ of PAE-azo-DCN and PAE-azo-CoPc were

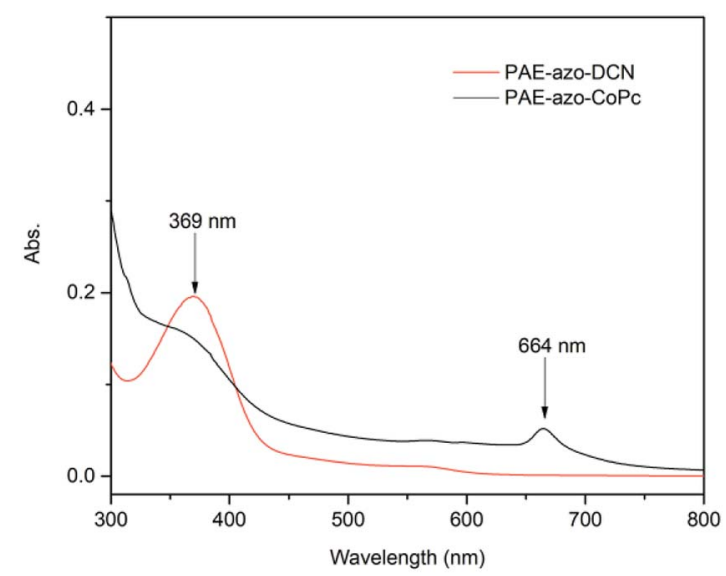

Fig. 4 UV-vis spectra of PAE-azo-DCN and PAE-azo-CoPc in DMF solution.

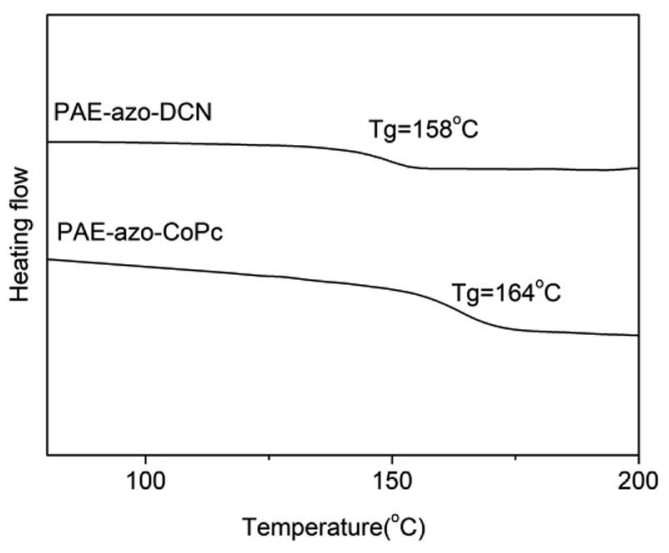

Fig. 5 DSC curves of PAE-azo-DCN and PAE-azo-CoPc.

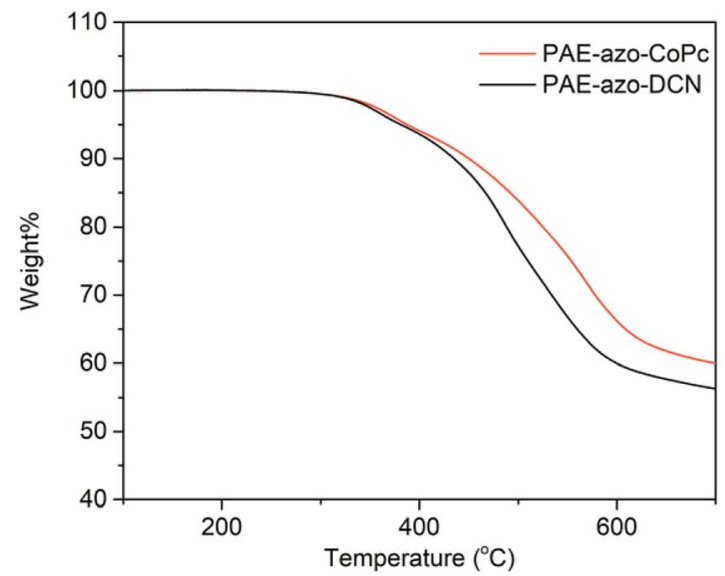

Fig. 6 TGA curve of PAE-azo-DCN and PAE-azo-CoPc in nitrogen.

above $380{ }^{\circ} \mathrm{C}$, indicating their good thermal stability. Compared to $T_{\mathrm{d} 5}$ of PAE-azo-DCN, $T_{\mathrm{d} 5}$ of PAE-azo-CoPc increased from $381{ }^{\circ} \mathrm{C}$ to $387^{\circ} \mathrm{C}$ after the introduction of phthalocyaninecobalt groups. Compared to the other azo-polymer optical limiting materials, ${ }^{33-36}$ both of PAE-azo-DCN and PAE-azo-CoPc showed better thermal stabilities, which could be attributed to the aromatic rigid structure of poly(arylene ether)s and phthalocyanines.

\subsection{Transparency of the films of the polymers}

To verify the feasibility of the material application, the films of the polymers was prepared as follow. The polymers were dissolved in dried DMF (10 wt\%). After stirring for $1 \mathrm{~h}$, the solution was filtered through $0.45 \mu \mathrm{m}$ syringe filter membranes. The films were obtained via spin-coating the solution onto clean silica glass substrates. After drying under vacuum for $24 \mathrm{~h}$, the films were obtained. The transparency of the films was measured with a Shimadzu UV-2501 UV-vis spectrophotometer. The films were about $5 \mu \mathrm{m}$ thick. As shown Fig. 7, the films of the polymers showed good transmittance (above $40 \%$ ) at $450-$ $800 \mathrm{~nm}$.

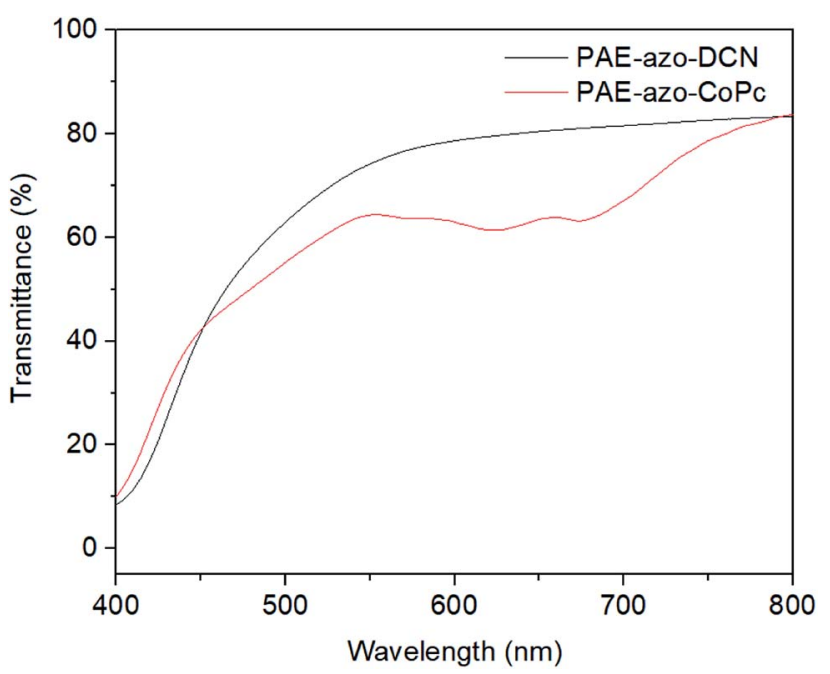

Fig. 7 The transmittance (\%) of the films of the polymers. 


\subsection{Nonlinear optical properties}

The nonlinear absorption coefficients of the polymers in DMF were measured using $\mathrm{Z}$ scan technique. As shown in Fig. 8, the results of $\mathrm{Z}$ scan with and without an aperture indicated that all the polymers had both nonlinear absorption and refraction. Thus, the third-order nonlinear optical susceptibilities $\chi^{(3)}$ of the polymers should be attributed to nonlinear absorption $\left(\alpha_{2}\right)$ and refractive $\left(n_{2}\right)$. The nonlinear absorption coefficient $\alpha_{2}$ of the polymers can be determined by the experimental data based on eqn (1) and (2):

$$
\begin{aligned}
& T(z, s=1)=\sum_{m=0}^{\infty} \frac{\left[-q_{0}(z)\right]^{m}}{(m+1)^{3 / 2}}\left|q_{0}\right|<1 \\
& q_{0}(z)=\alpha_{2} I_{0}(t) L_{\mathrm{eff}}\left(\left(1+z_{2}+z_{0}^{2}\right)\right.
\end{aligned}
$$

In the equation, $I_{0}(t)$ was the intensity of laser beam at focus $(z$ $=0) ; L_{\text {eff }}=\left[1-\exp \left(-\alpha_{0} L\right)\right] / \alpha_{0}$ was the effective thickness; $\alpha_{0}$ was the linear absorption coefficient; $L$ was the sample thickness; $z$ was the sample position; $z_{0}$ was the diffraction length of the beam. The curves in Fig. 8(a) and (c) are obtained from eqn (1) and (2). As shown in Table 2, the nonlinear absorption coefficient $\alpha_{2}$ of PAE-azo-DCN was $-6 \times 10^{-11}$ esu which corresponded to saturable absorption, and the nonlinear absorption coefficient $\alpha_{2}$ of PAE-azo-CoPc was $2 \times 10^{-10}$ esu which corresponded to reverse saturable absorption of cobalt phthalocyanine.

$$
T(z, \Delta \Phi)=1+\frac{4 \Delta \Phi x}{\left(x^{2}+9\right)\left(x^{2}+1\right)}
$$

The nonlinear refractive coefficient $n_{2}$ of the polymers can be determined by the experimental data based on eqn (3). In the equation, $x=z / z_{0}$ and $\Delta \Phi$ is the on-axis phase change caused by the nonlinear refractive index of the sample and $\Delta \Phi=\left[2 \pi I_{0}(1-\right.$ $\left.\left.\mathrm{e}^{-\alpha_{0} L}\right) n_{2}\right] /\left(\lambda \alpha_{0}\right)$. The curves in Fig. 8(b) and (d) are obtained from eqn (3). As shown in Table 2, the nonlinear refractive coefficient $n_{2}$ of PAE-azo-DCN was $-2.5 \times 10^{-17}$, and the nonlinear refractive coefficient $n_{2}$ of PAE-azo-CoPc was $3 \times 10^{-17}$.

$$
\left|\chi^{(3)}\right|=\sqrt{\left|\frac{c n_{0}}{80 \pi} n_{2}\right|^{2}+\left|\frac{9 \times 10^{8} \varepsilon_{0} n_{0}^{2} c^{2}}{4 \pi \omega} \alpha_{2}\right|^{2}}
$$

The $\chi^{(3)}$ can be calculated by the eqn (4). In the equation, $\varepsilon_{0}$ is the permittivity of vacuum; $c$ is the speed of light; $n_{0}$ is the refractive index of the medium; $\omega=2 \pi c / \lambda$. By calculated from eqn (4), the nonlinear susceptibilities of PAE-azo-CoPc and PAEazo-DCN are $5.18 \times 10^{-11}$ esu and $4.27 \times 10^{-11}$ esu, respectively. The reason of the improving of nonlinear susceptibilities was the introduction of phthalocyaninecobalt groups. In additon, both of the two polymers showed larger nonlinear susceptibilities than those of other azobenzene-containing poly(aryl ether) (azo-PAE) ${ }^{29}$ or other azo-polymer systems. ${ }^{37-39}$ The increase of the nonlinear susceptibilities could be attributed to the aromatic rigid structure of poly(arylene ether)s and the large conjugated structure of the phthalocyanine.
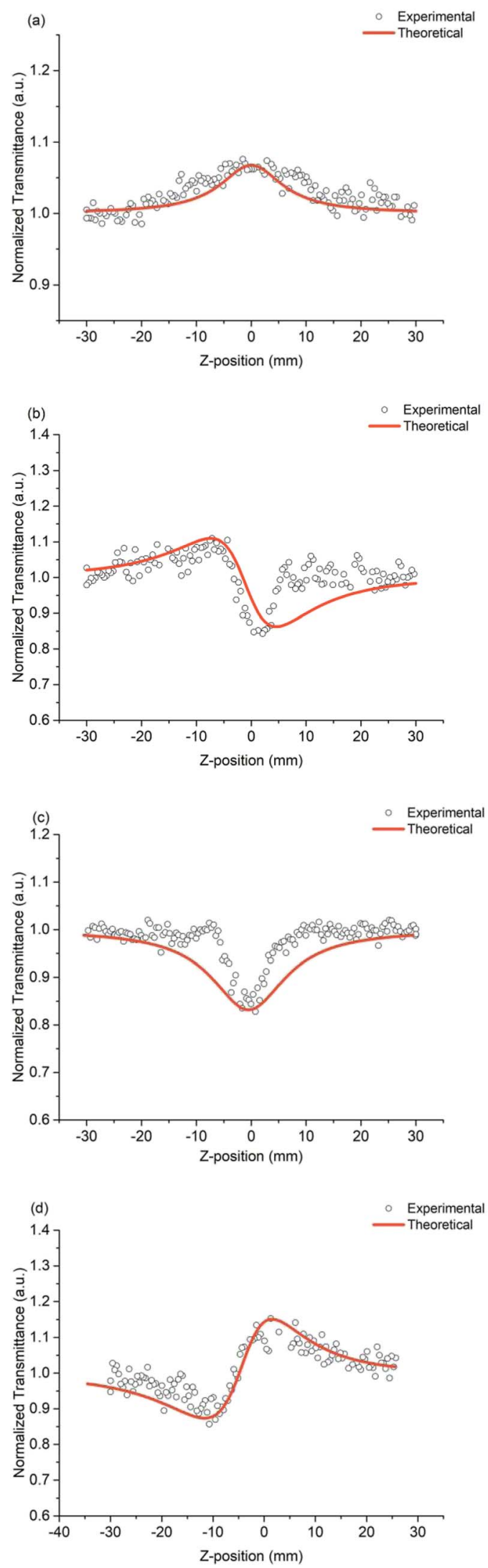

Fig. 8 Z-scan data of (a) PAE-azo-DCN (open aperture), (b) PAE-azoDCN (close aperture), (c) PAE-azo-CoPc (open aperture), and (d) PAEazo-CoPc (close aperture). 
Table 2 Nonlinear Properties of PAE-azo-DCN and PAE-azo-CoPc

\begin{tabular}{lrrl}
\hline Polymer & \multicolumn{1}{c}{$\alpha_{2}$} & \multicolumn{1}{l}{$n_{2}$} & $\chi^{(3)}$ \\
\hline PAE-azo-DCN & $-6 \times 10^{-11}$ & $-2.5 \times 10^{-17}$ & $4.27 \times 10^{-11}$ \\
PAE-azo-CoPc & $2 \times 10^{-10}$ & $3 \times 10^{-17}$ & $5.18 \times 10^{-11}$
\end{tabular}

\subsection{Optical limiting properties}

The optical limiting performance of PAE-azo-CoPc were measured in DMF with the same Z-scan technique system as in the nonlinear absorption experiment. The curves of normalized transmittance versus input fluence of PAE-azo-CoPc was show in Fig. 9. As shown in Fig. 9, PAE-azo-CoPc showed well OL performance with the limiting threshold (incident fluence at which the transmittance falls to $50 \%$ of the linear transmittance) of $0.038 \mathrm{~J} \mathrm{~cm}^{-2}$. The curves of output fluence versus input fluence of PAE-azo-CoPc was show in Fig. 10. As shown in Fig. 10, the output fluence linearly increased with the incident fluence obeying the Beer-Lambert law at low-incident fluence. However, at high-incident fluence, the output fluence deviated from linearity, showed typical behavior of optical limiting response.

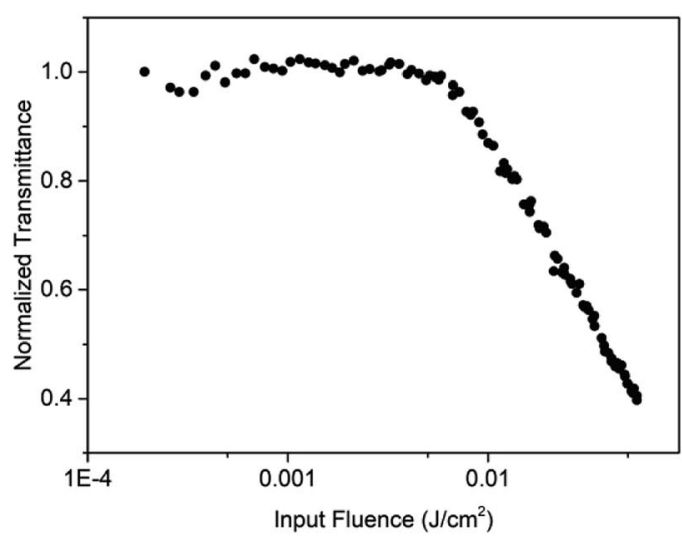

Fig. 9 Optical limiting response of PAE-azo-CoPc in DMF.

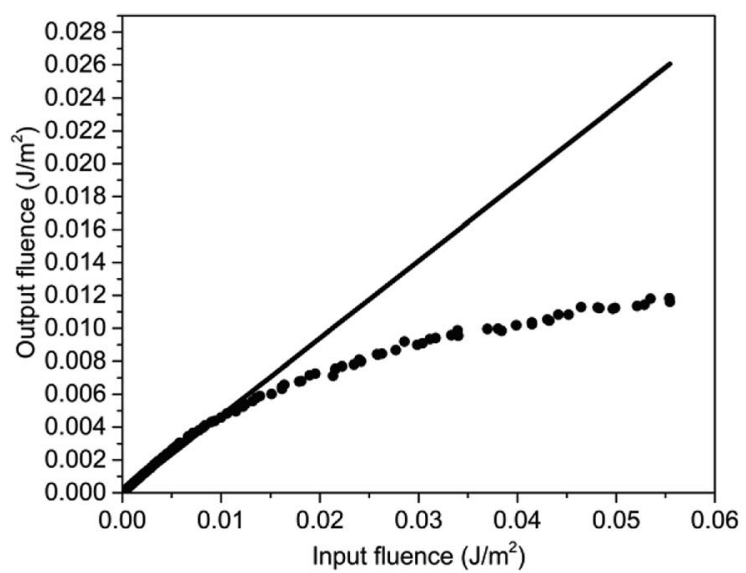

Fig. 10 The curves of output fluence versus input fluence of PAE-azoCoPc in DMF.

\section{Conclusions}

In this work, a novel kind of poly(arylene ether)s with azocoupled cobalt phthalocyanine in the side chain (PAE-azo$\mathrm{CoPc}$ ) was prepared by 1,2-benzodinitrile, cobaltous chloride anhydrous and a novel azobenzene-containing poly(aryl ether) (PAE-azo-DCN). Both of the polymers exhibited high glass transition temperature $\left(T_{\mathrm{g}}>158{ }^{\circ} \mathrm{C}\right)$ and good thermal stability $\left(T_{\mathrm{d} 5}>380^{\circ} \mathrm{C}\right)$. PAE-azo-CoPc exhibited higher glass transition temperature and better thermal stability than PAE-azo-DCN due to the introduction of cobalt phthalocyanine groups. The results of Z-scan measurements demonstrated that PAE-azo-CoPc showed reverse saturable absorption and positive refraction, and PAE-azo-DCN showed saturable absorption and negative refraction. PAE-azo-CoPc exhibited larger third-order nonlinear optical susceptibilities than that of PAE-azo-DCN. The results of optical limiting measurements demonstrated that PAE-azoCoPc showed well OL performance with the limiting threshold of $0.038 \mathrm{~J} \mathrm{~cm}^{-2}$. PAE-azo-CoPc could be expected to be a potential material for optical limiting, optical switching and other optical applications. This work provided a novel path for designing new excellent optical limiting materials with good thermal stability.

\section{Conflicts of interest}

There are no conflicts to declare.

\section{Acknowledgements}

The authors gratefully acknowledge the National Natural Science Foundation of China (Grant No. 51703089 and No. 51773085) for financial support.

\section{References}

1 L. W. Tutt and A. Kost, Nature, 1992, 356, 225-226.

2 L. W. Tutt and T. F. Boggess, Prog. Quantum Electron., 1993, 17, 299-338.

3 C. W. Spangle, J. Mater. Chem., 1999, 9, 2013-2020.

4 T. J. Mckay, J. Staromlynska, P. Wilson and J. Davy, J. Appl. Phys., 1999, 85, 1337-1341.

5 J. Wang, Y. Chen and W. J. Blau, J. Mater. Chem., 2009, 19, 7425-7443.

6 Y. Chen, T. Bai, N. N. Dong, F. Fan, S. F. Zhang, X. D. Zhuang, J. Sun, B. Zhang, X. Y. Zhang, J. Wang and W. J. Blau, Prog. Mater. Sci., 2016, 84, 118-157.

7 G. Muruganandi, M. Saravanan, G. Vinitha, M. S. J. Raj and T. C. S. Girisun, Opt. Mater., 2018, 75, 612-618.

8 M. V. Srinivasan and P. Kannan, J. Mater. Sci., 2011, 46, 50295043.

9 P. Gautam, B. Dhokale, V. Shukla, C. P. Singh, K. S. Bindra and R. Misra, J. Photochem. Photobiol., A, 2012, 239, 24-27.

10 Z. H. Shi, Y. S. Zhou, L. J. Zhang, C. C. Mu, H. Z. Ren, D. Hassan, D. Yang and H. M. Asifa, RSC Adv., 2014, 4, 50277-50284. 
11 Y. Chen, M. Hanack, W. J. Blau, D. Dini, J. J. Doyle, Y. Liu, Y. Lin and J. R. Bai, J. Mater. Sci., 2006, 41, 2169-2185.

12 Y. X. Zhang and Y. H. Wang, RSC Adv., 2017, 7, 45129-45144.

13 M. O. Senge, M. Fazekas, E. G. A. Notaras, W. J. Blau, M. Zawadzka, O. B. Locos and E. M. N. Mhuircheartaigh, Adv. Mater., 2007, 19, 2737-2774.

14 M. Calvete, G. Y. Yang and M. Hanack, Synth. Met., 2004, 141, 231-243.

15 N. J. Li, J. M. Lu, Q. F. Xu and L. H. Wang, Opt. Mater., 2006, 28, 1412-1416.

16 T. Ushiwata, E. Okamoto, K. Komatsu, T. Kaino and A. K. Y. Jen, Opt. Mater., 2002, 21, 61-65.

17 Y. Chen, M. Hanack, Y. Araki and O. Ito, Chem. Soc. Rev., 2005, 34, 517-529.

18 N. Nwaji, J. Mack, T. Nyokong and T. Nyokong, J. Photochem. Photobiol., A, 2005, 352, 73-85.

19 P. Zhao, Z. H. Wang, J. S. Chen, Y. Zhou and F. S. Zhang, Opt. Mater., 2017, 66, 98-105.

20 Z. H. Chen, C. Zhong, Z. Zhang, Z. Y. Li, L. H. Niu, Y. J. Bin and F. S. Zhang, J. Phys. Chem. B, 2008, 112, 7387-7394.

21 M. A. Ozdag, A. Mehmet Ali, T. Ceyhan, H. G. Yaglioglu, A. Elmali and O. Bekaroglu, Opt. Laser Technol., 2011, 43, 992-995.

22 J. Britton, C. Litwinski, E. Antunes, M. Durmus, V. Chaukea and T. Nyokong, J. Macromol. Sci., Part A: Pure Appl. Chem., 2013, 50, 110-120.

23 O. M. Bankole and T. Nyokong, J. Coord. Chem., 2015, 68, 3727-3740.

24 E. M. Maya, G. de la Torre, A. E. Lozano, T. Torres, J. G. de la Campa and J. de Abajo, Macromol. Rapid Commun., 2006, 27, 1852-1858.

25 T. F. Wang, X. Wang, J. L. Zhang, C. R. Wang, J. F. Shao, Z. H. Jiang and Y. H. Zhang, Dyes Pigm., 2018, 154, 75-81.

26 Y. X. Zhang, S. H. Pei, Y. P. Wang, Z. D. Cui, N. Li, Y. Zhu, H. B. Zhang and Z. H. Jiang, Dyes Pigm., 2013, 99, 1117-1123.
27 Y. X. Zhang, J. J. Zhang, Z. D. Cui, Q. D. Chen, H. B. Zhang and Z. H. Jiang, J. Polym. Sci., Part A: Polym. Chem., 2015, 53, 936-943.

28 D. Liu, Z. G. Wang, H. Yu and J. You, Eur. Polym. J., 2009, 45, 2260-2268.

29 H. B. Zhang, J. H. Pang, D. Wang, X. F. Li and Z. H. Jiang, J. Membr. Sci., 2006, 264, 56-64.

30 X. B. Chen, J. J. Zhang, H. B. Zhang, Z. H. Jiang, G. Shi and Y. L. Song, Dyes Pigm., 2008, 77, 223-228.

31 Y. L. Du, K. Zhu, Y. Fang, S. L. Zhang, X. R. Zhang, T. N. Lu, Y. C. Yang, Y. L. Song and G. B. Wang, RSC Adv., 2015, 5, 48311-48322.

32 Y. L. Du, S. L. Zhang, X. Jiang, K. Zhu, Z. Geng, Y. Fang, P. F. Huo, C. Liu, Y. L. Song and G. B. Wang, J. Polym. Sci., Part A: Polym. Chem., 2014, 52, 1282-1290.

33 G. Zhao, G. Wei, W. J. Zhu, F. Y. Ke, S. Y. Guang, F. Y. Zhang and H. Y. Xu, J. Appl. Polym. Sci., 2019, 135, 46100.

34 Y. L. Lei, F. D. Ma, Y. Tian, Q. L. Niu, H. Y. Mi, I. Nurulla and . Shi, J. Appl. Polym. Sci., 2013, 129, 1763-1772.

35 F. A. Nicolescu, V. V. Jerca, I. Dancus, A. Petris, T. V. Nicolescu, I. B. Rau, V. I. Vlad, D. S. Vasilescu and D. M. Vuluga, J. Polym. Res., 2011, 18, 1009-1016.

36 J. Illesca, Y. S. Ramirez-Fuentes, E. Rivera, O. G. MoralesSaavedra, A. A. R. Guez-Rosales, V. Alzari, D. Nuvoli, S. Scognamillo and A. Mariani, J. Polym. Sci., Part A: Polym. Chem., 2011, 49, 3291-3298.

37 C. Zhang, Y. L. Song, X. Wang, F. E. Kuhn, Y. X. Wang, Y. Xu and X. Q. Xin, J. Mater. Chem., 2003, 13, 571-579.

38 F. Cherioux, P. Audebert, H. Maillotte, L. Grossard, F. E. Hermamdez and A. Lacourt, Chem. Mater., 1997, 9, 2921-2927.

39 O. Varnavski, R. G. Ispasoiu, M. Narewal, J. Fugaro, Y. Jin, H. Pass and T. Goodson III, Macromolecules, 2000, 33, 4061-4068. 